\title{
Ações pedagógicas colaborativas e inclusivas na percepção do professor da educação básica e intérprete de libras no processo de formação continuada
}

\author{
Collaborative and inclusive pedagogical actions in the perception \\ of mathematics teacher and interpreter of pounds \\ In the process of continuous training
}

\author{
Rozelaine de Fatima Franzin ${ }^{1}$ \\ Marlise Geller²
}

\begin{abstract}
Resumo
Este artigo teve como ponto de partida pesquisa realizada com intérpretes de Libras e professores de matemática que trabalham com alunos surdos no Instituto Federal Farroupilha, Campus Santo Ângelo/RS. Pela entrevista semiestruturada realizada surgiram percepções e sugestões de ações para serem desenvolvidas e utilizadas na forma de oficinas em formação continuada para professores da Educação Básica. Na segunda etapa a proposta foi aplicada a professores da Rede Pública Estadual que trabalham com alunos surdos incluídos em Escola Regular de Ensino e alunos ouvintes, e teve como objetivo promover, de forma colaborativa, ações pedagógicas visando à formação continuada, na perspectiva da Educação Inclusiva. Nesse contexto, apresenta apontamentos teóricos e práticos, os quais abordam aspectos relacionados a inclusão, formação continuada de professores e metodologias para serem utilizados em processo avaliativo e de elaboração de práticas pedagógicas em sala de aula. Além de relatos de alguns professores participantes da pesquisa e da palestrante surda oralizada.
\end{abstract}

\footnotetext{
${ }^{1}$ Pós- doutoranda pela Universiddae Luterana do Brasil-ULBRA. Doutora em Engenharia de Produção pela Universidade Federal de Santa Catarina (2007), Mestrado em Engenharia de Produção pela Universidade Federal de Santa Maria (2000), especialização em Matemática Integrada Regional Alto Uruguai e Missões (1998), graduação em Matemática pela Universidade Regional Integrada do Uruguai e Missões (1990). Atualmente é professora em tempo integral na Universidade Regional Integrada do Alto Uruguai e Missões, atuando na graduação, especialização e no mestrado profissional em ensino científico e tecnológico e professora aposentada do Instituto Estadual de Educação Odão Felippe Pippi. Tem experiência na área de Matemática e Estatística, atuando principalmente nos seguintes temas: softwares estatísticos, aprendizado matemático, ambientes virtuais de aprendizagem inclusivos, práticas de ensino e formação de professores. Coordenadora do LIPI - Laboratório Interativo de Práticas Inclusivas. E-mail: rozelaine@santoangelo.uri.b.

${ }^{2}$ Mestrado em Educação pela Pontifícia Universidade Católica do Rio Grande do Sul (1995) e doutorado em Informática na Educação pela Universidade Federal do Rio Grande do Sul (2004). Atualmente é professora adjunta da Universidade Luterana do Brasil, atuando no curso de Pedagogia e no PPGECIM (Programa de Pós-Graduação em Ensino de Ciências e Matemática). Principais interesses de pesquisa envolvem: Informática na Educação, Educação a Distância, Formação continuada de professores, Educação Inclusiva, Tecnologias Assistivas e inclusão digital. Atuou como professora-pesquisadora da Universidade Aberta do Brasil no projeto de Formação Continuada de Professores em Tecnologias da Informação e Comunicação Acessíveis (2001-2012). Coordenadora do LEI - Laboratório de Estudos de Inclusão do PPGECIM. Líder do Grupo de Pesquisa cadastrado no CNPq: Ensino de Ciências e Matemática na perspectiva da Educação Inclusiva. E-mail: marlise.geller@gmail.com.
}

Interfaces da Educ., Paranaíba, v.10, n.30, p. 290 - 314', 2019 ISSN 2177-7691 
Palavras-chave: Formação continuada de professores. Ações Inclusivas. Educação Básica. Surdez.

\begin{abstract}
This article had as its starting point research carried out with Libras interpreters and math teachers who work with deaf students at the Farroupilha Federal Institute, Campus Santo Ângelo / RS. Through the semistructured interview, perceptions and suggestions for actions emerged to be developed and used in the form of workshops in continuing education for teachers of Basic Education. In the second stage, the proposal was applied to teachers of the State Public Network who work with deaf students included in Regular Teaching School and hearing students, and aimed to collaboratively promote pedagogical actions aimed at continuing education, from the perspective of Inclusive Education. In this context, presents theoretical and practical notes, which address aspects related to inclusion, continuing education of teachers and methodologies to be used in the evaluation process and the development of pedagogical practices in the classroom. In addition to reports of some teachers participating in the research and the oral deaf speaker.
\end{abstract}

Keywords: Continuing Education. Inclusive Actions. Mathematics Education. Deafness.

\title{
Introdução
}

A Educação Inclusiva é hoje uma realidade, embora haja carência de capacitação docente e questionamentos na condução do processo, sendo ainda um desafio atender às diversidades apresentadas pelos estudantes (NASCIMENTO; GELLER, 2015).

Em relação aos alunos surdos, as instituições escolares não têm apenas o compromisso de atendê-los, mas deve proporcionar a esses alunos, professores capacitados para de fato inclui-los. Nem sempre o intérprete de Libras está disponivel nas escolas, o que gera um desconforto para o professor que não consegue muitas vezes suprir a lacuna gerada na aprendizagem por não saber se comunicar com seu aluno surdo. Mesmo o intérprete estando presente em sala de aula, há momentos em que o aluno não pode contar com seu auxílio como em tarefas extraclasses ou 'mesmo nas avaliações. 
A presente pesquisa é um recorte de um trabalho de pós-doutorado na área de Ensino de Ciências e Matemática e originou-se das entrevistas com professores e intérpretes de Libras do Instituto Federal Farroupilha - IFFar, Campus Santo Ângelo/RS e a partir dessas, foram propostas e desenvolvidas ações pedagógicas para formação continuada, construídas de forma colaborativa pelo grupo participante do estudo.

Diante desse contexto, o estudo se justifica pela proposição das ações que visam à formação continuada de professores de forma a prepará-los para atuar com alunos surdos, numa perspectiva de intervenções pedagógicas inclusivas centradas no processo de aprendizagem do aluno. Com base na análise das informações coletadas ao longo da pesquisa foram realizados encontros para discutir ações e troca de experiências com intérpretes de Libras e professores que têm ou tiveram alunos surdos e, de forma colaborativa, sugeriram ações pedagógicas que contemplaram as necessidades levantadas pelos professores de matemática, com o objetivo de promover estratégias de capacitação para uma prática docente mais inclusiva em sala de aula.

\section{Educação Inclusiva}

Nas escolas regulares de ensino, a inclusão é um direito garantido por lei proporcionando novas experiências e o desenvolvimento de habilidades e aprendizagens significativas.

\footnotetext{
De acordo com a Resolução $\mathrm{n}^{\circ} 2$, de 11 de setembro de 2001, no seu $\operatorname{Art}^{\circ} 2^{\circ}$, fica claro que os "sistemas de ensino devem matricular todos os alunos, cabendo às escolas organizar-se para o atendimento aos alunos com necessidades educacionais especiais, assegurando as condições necessárias para uma educação de qualidade para todos", bem como no $\mathrm{Art}^{\circ} 7^{\circ}$ diz que "o atendimento aos alunos com necessidades educacionais especiais" deve ser realizado em classes comuns do ensino regular, em qualquer etapa ou modalidade da Educação Básica (BRASIL, 2001, p. 1, 2).
}

Ainda objetiva a participação e permanência das pessoas portadoras de necessidades especiais no contexto escolar, buscando seu desenvolvimento intelectual e social nos diversos ambientes nos quais esses cidadãos estão inseridos. 
As escolas regulares com professores capacitados, que possam auxiliar no desenvolvimento das potencialidades de todos os alunos, principalmente aqueles com deficiência, por sua vez os espaços educacionais devem estar preparados, com profissionais que possam efetivamente colocar a inclusão escolar em prática (COLLING; GELLER, 2019).

A região de abrangência da $14^{\mathrm{a}} \mathrm{CRE}$ - Coordenadoria Regional de Educação não possui escola de Educação Especial, constituindo-se em mais um motivo para que os alunos com deficiência sejam incluídos nas escolas da Rede Regular de Ensino.

O número de matrículas de alunos com deficiência, transtornos globais do desenvolvimento e/ou altas habilidades/superdotação em classes comuns (incluídos) ou em classes especiais exclusivas chegou a 1,2 milhão em 2018, um aumento de 33,2\% em relação a 2014. Esse aumento foi influenciado pelas matrículas de ensino médio que dobraram durante o período. Considerando apenas os alunos de 4 a 17 anos da educação especial, verifica-se que o percentual de matrículas de alunos incluídos em classe comum também vem aumentando gradativamente, passando de $87,1 \%$ em 2014 para 92,1\% em 2018. (INEP, 2018).

Por esse motivo, as Escolas Regulares de Ensino devem estar preparadas para receber esses alunos, proporcionando experiências e desenvolvimento de aprendizagens significativas, tanto para alunos ouvintes como para alunos surdos. Segundo Zwan et al (2016, p.19), "é importante que esses ambientes proporcionem condições necessárias para que os surdos desenvolvam suas habilidades e aprendizagens em iguais condições aos demais individuos".

Além disso, é preciso adequar os currículos escolares, considerando essa diferença de aprendizagem ainda no ingresso à escola, pois, se há uma dificuldade e esta persiste para a maioria dos surdos, essa adaptação é necessária se os objetivos forem um ensino e um aprendizado de boa qualidade.

Para que cada ação pedagógica seja resultado de um processo de aprendizagem para o aluno, a escola deve organizar os conteúdos curriculares de forma que contribua para a sua formação enquanto agentes sociais. (NASCIMENTO et al., 2015, p.5).

Nos últimos anos, muitos alunos surdos foram incluídos em turmas regulares de ensino, mas será que a aprendizagem desses alunos está sendo 
atendida completamente? Porém, pode-se questionar se no ambiente escolar, gestores, funcionários e professores estão preparados de fato para atendê-los.

[...] incluir não é somente o aluno frequentar a escola regular, mas dispor de recursos necessários para seu desenvolvimento cognitivo e intelectual, enquanto cidadão em processo de formação. Para tanto, o sistema educacional precisa estar devidamente adaptado para proporcionar-lhes um ambiente adequado de aprendizagem. (FRANZIN, ZWAN, ROSINSKI, 2016, p.21).

Muitos avanços em relação à educação de surdos têm ocorrido nos últimos anos, mas ainda se têm um longo caminho a percorrer e dentro deste contexto, salienta-se a formação do professor para melhor atender esse aluno surdo.

Os professores na sua maioria precisam de capacitação para obtenção de conhecimento necessário para organizar suas aulas dentro desse contexto, adotando metodologias e estratégias adequadas para alunos surdos. É necessário entender como seus alunos surdos constroem o conhecimento para poder auxiliá-los nesse processo e partindo desse pressuposto, planejar suas aulas dentro da perspectiva inclusiva.

Numa escola inclusiva, o aluno é sujeito de direito e foco central de toda ação educacional; garantir a sua caminhada no processo de aprendizagem e de construção das competências necessárias para o exercício pleno da cidadania é, por outro lado, objetivo primeiro de toda ação educacional. (NASCIMENTO et al., 2015, p.6).

O uso de estratégias e metodologias próprias para que a inclusão realmente aconteça deve ser prioridade entre os professores. Muitas vezes isso não ocorre por falta de formação adequada ou capacitação específica.

Nesse contexto, a escola deve fazer sua parte e oferecer aos professores condições para o desenvolvimento de seu trabalho com espaço e tempo, oportunizando debates sobre as dificuldades encontradas bem como dispor de formação e acesso a materiais pedagógicos.

Para Nascimento et al. (2015, p.11), "Não basta ter uma escola inclusiva, mas dar meios para melhorar o ensino aprendizagem dos surdos como materiais visuais, acesso à internet e formação aos docentes para ensinar os surdos". 
É preciso desenvolver competências e habilidades voltadas para a construção desse conhecimento, mediado por metodologias de ensino adequadas para que o processo de ensino seja atingido.

E quando se trata de educação de surdos, a metodologia de ensino se
torna muito importante, uma vez que se está trabalhando com pessoas
pertencentes a uma cultura diferente, que pensam e desenvolvem seu
conhecimento de forma diferente. Devemos adequar a metodologia que
utilizamos ao público que nós atendemos, para que estes possam
pensar, construir e expressar seu conhecimento satisfatoriamente.
(MIRANDA; MIRANDA, 2011, p. 43).

Para auxiliar o professor nessa perspectiva mais inclusiva, o uso da metodologia colaborativa pode ser um dos caminhos na formação continuada, podendo promover uma aprendizagem mais ativa, pois estimula o professor na construção de conhecimentos para inseri-lo no ambiente escolar inclusivo mais preparado. Essa construção se dá pela troca de experiências levando-se em consideração os conhecimentos prévios dos envolvidos no estudo, nesse caso, professores e intérpretes. Com isso, há uma maior interação e compartilhamento de informações facilitando a aprendizagem pelo conhecimento construído.

Pode-se dizer que a aprendizagem colaborativa é muito mais que uma técnica de sala de aula, é "uma maneira de lidar com as pessoas que respeita e destaca as habilidades e contribuições individuais de cada membro do grupo" (PANITZ, 1996, p.1).

Assume-se que todos os envolvidos possuam habilidades sociais para trabalhar em grupo dando um feedback construtivo da participação e desempenho para a resolução de problemas com tarefas direcionadas, sem avaliação do desenvolvimento das mesmas.

Essas novas práticas estimulam uma socialização no processo de ensino-aprendizagem, em que indivíduos em grupos solucionam problemas em comum e, acima de tudo, constroem conhecimento socialmente relevante (IRALA, 2005 apud TORRES; IRALA, 2014, p.69).

Nessa abordagem, o conhecimento é compartilhado com trocas de conhecimentos entre professores e intérpretes tornando a aprendizagem de responsabilidade de cada um e fazendo com que o conhecimento seja 
multiplicado e replicado, viabilizando o sucesso do ensino colaborativo. Contribuindo com esse pensamento, destaca-se que

\begin{abstract}
A pesquisa colaborativa difere de práticas tradicionais de investigação na medida em que o professor deixa de ser o objeto de estudo do pesquisador e passa a ser participante desse processo, com oportunidade de refletir e mudar sua prática docente. (BORBA; ALMEIDA; GRACIAS, 2018, p.48).
\end{abstract}

Nesse sentido, é possivel elaborar de forma colaborativa estratégias pedagógicas, possibilitando ao professor sentir-se mais preparado para efetivar o processo de inclusão.

Em relação a formação de professores, entende-se que "estamos lidando com o aprimoramento de profissionais que atuarão diretamente na construção cognitiva e social de seres humanos, então estes profissionais devem estar preparados para compreender as necessidades cognitivas e afetivas que seus alunos estão necessitando, para encontrar estratégias e efetivar aprendizagens" (FELIPE; GELLER, 2019, p.3).

\title{
Metodologia da Pesquisa
}

A investigação está baseada na aprendizagem colaborativa com abordagem qualitativa, na perspectiva de Gerhardt e Silveira (2009), preocupa-se, portanto, com aspectos da realidade que não podem ser quantificados, centrando-se na compreensão e explicação da dinâmica das relações sociais.

Classifica-se como pesquisa ação, pela interação entre os professores, intérprete de Libras e pesquisadores com trabalho em grupo e a construção colaborativa do conhecimento. $\mathrm{Na} 1^{\mathrm{a}}$ parte da pesquisa na coleta de dados usou-se a técnica de grupo focal em que o pesquisador ouve e observa os participantes e suas interações no contexto do grupo colhendo informações, sentimentos, percepções, experiências e expectativas sobre um determinado tema. Na $2^{a}$ parte de coleta de dados foi utilizado a observação participante e entrevistas. A observação participante contribui em grande medida com a pesquisa colaborativa, gerando dados descritivos sobre as experiências de ensino desenvolvidas. Na pesquisa colaborativa o pesquisador se envolve na realidade atuando conjuntamente com os sujeitos participantes do estudo de 
modo a levantar problemáticas e propor soluções com os sujeitos (RABELO, 2012).

Os suportes teóricos nessa investigação se sustentam nos processos inclusivos, capacitação docente e método de aprendizagem colaborativa.

A pesquisa foi estruturada em duas etapas que foram organizadas da seguinte forma: o estudo iniciou em setembro de 2018, sendo a primeira etapa dividida em dois (2) momentos: o primeiro com duração de 6 meses foi realizado usando entrevistas semiestruturadas com todos os participantes da pesquisa que buscou discutir suas práticas, a interface entre a atuação do professor de matemática em sala regular e do intérprete de Libras e no tocante ao processo de ensino desses professores no ambiente inclusivo, sendo realizado na Universidade Federal Farroupilha - IFFar, Campus de Santo Ângelo, por possuir uma concentração maior de alunos surdos do que em outras instituições, disponibilizando assim mais professores com experiência em atendimento desses alunos para a realização desta pesquisa.

O segundo momento iniciou em fevereiro de 2019, com duração de 3 meses, contemplou numa $1^{\mathrm{a}}$ etapa de forma colaborativa trocas de experiências envolvendo casos sobre o papel do intérprete de Libras, avaliação, percepção do docente em relação ao português como segunda língua e a matemática como terceira língua e as práticas docentes inclusivas realizadas por esses professores.

Com base na análise das informações obtidas foram elaboradas de forma colaborativa ações pedagógicas que posteriormente foram ofertadas aos professores em cursos de formação continuada. As estratégias elaboradas contemplaram as necessidades levantadas pelos professores de matemática tendo como finalidade a incorporação das mesmas na sua prática educativa. Após, as estratégias foram sistematizadas considerando os pontos a serem melhorados. A segunda etapa materializou-se com a aplicação das ações propostas em formação continuada com professores de diversas áreas e também alunos do curso de magistério que se propuseram a participar da pesquisa, do Instituto Educacional Estadual Odão Felippe Pippi, escola de educação básica onde a pesquisadora atuou como docente. A aplicação das 
ações foi dividida em 4 encontros com duração de $2 \mathrm{~h}$ cada um, com início em maio de 2019 e duração de 3 meses.

\section{Proposta de Ações Inclusivas para Formação Continuada Docente}

A proposta tem como finalidade oportunizar ao professor, por meio de ações inclusivas, sua inserção de forma mais efetiva no ambiente escolar com alunos surdos, além de dispor algumas sugestões de ações que venham a facilitar esse processo e a prática pedagógica dos docentes.

Foi baseada inicialmente pela manifestação dos professores de matemática e intérpretes de Libras pesquisados na primeira etapa do desenvolvimento da pesquisa. Foram sugeridas algumas ações para auxiliar o professor na sua prática pedagógica, junto ao aluno surdo e também em atividades avaliativas.

A proposta foi dividida em 4 etapas dispostas da seguinte forma:

- $1^{a}$ etapa: Palestra de sensibilização - essa etapa serviu para o professor conhecer a legislação vigente e poder cobrar providências do poder público, caso seja necessário. Portanto, deve-se sensibilizar a comunidade escolar para a importância do professor estar preparado para receber o aluno surdo na escola. A palestra abordou a conceituação das deficiências, sujeitos incluídos e compreensão dos aspectos referentes à educação inclusiva, legislação e contexto histórico.

- $2^{\text {a }}$ etapa: Seminário - essa etapa contemplou metodologias que se enquadram para o ensino de alunos surdos, considerando as particularidades no processo de aprendizagem desses alunos.

- $3^{a}$ etapa: Oficinas - na terceira etapa foi proposto oficinas com o uso de recursos didáticos pedagógicos envolvendo tecnologias da informação, materiais concretos e auxílio na construção, de forma colaborativa, de planos de aula, avaliações e oficinas na perspectiva da educação inclusiva.

- 4a etapa: Grupos de estudos para continuidade das ações - nessa etapa a Direção da Escola deve se comprometer a proporcionar aos professores espaço e tempo para estudos e debates sobre o tema abordado, dando continuidade e ampliando os recursos e técnicas desenvolvidas nas atividades das oficinas. 
Essa etapa pode marcar o início dos grupos de estudos nas escolas que tem por objetivo possibilitar a diminuição da distância existente entre professores, intérpretes e a educação inclusiva no ambiente escolar.

\section{Discussão dos Resultados}

Para as questões investigativas foram obtidas informações que são expostas com suas respectivas análises. Na primeira etapa, a ação de sensibilização da comunidade escolar, participaram sessenta e uma pessoas, entre professores, gestores e alunos do curso normal. Após a palestra, um questionário foi aplicado aos participantes com questões gerais e específicas. As específicas, em número de quatro, sendo duas delas relacionadas a participação do público e duas referentes ao tema abordado pelo palestrante e suas respostas envolviam a seguinte escala de avaliação: ótima, muito boa, boa, regular e ruim. São elas:

1. Avaliação de seu desempenho e aproveitamento como participante;

2. Contribuição da palestra para aquisição de novos conhecimentos e melhoria do desempenho no trabalho;

3. Relevância do conteúdo abordado;

4. Troca de experiências entre os participantes da palestra e palestrante.

Dos sessenta e um participantes dessa etapa, trinta e quatro responderam o questionário e desses, treze eram normalistas e 3 gestores.

Das questões aplicadas, foram analisadas as questões 2 e 3, por serem mais relevantes ao tema abordado, que foram replicadas para todas as ações. Tanto para a questão 2, contribuição para a aquisição de novos conhecimentos e melhoria do desempenho no trabalho, como para a questão 3 , que trata da relevância do conteúdo abordado, nenhum respondeu regular ou ruim.

A inserção dos professores no contexto histórico conhecimento da legislação existente possibilitou aos mesmos aprofundar os conhecimentos prévios sobre o assunto e resultou numa maior clareza para que pudessem entender as dificuldades enfrentadas pelos alunos surdos em relação aos seus direitos em aprender de forma igualitária. 
$\mathrm{Na}$ segunda etapa, abordagem de metodologias inclusivas, o professor deve conhecer e se apropriar de metodologias de ensino para alunos surdos. Participaram quarenta e três pessoas.

Nessa ação, a palestrante mostrou possibilidades de metodologias para alunos surdos e contou sua experiência de aprendizagem e porquê se oralizou. Relatou que o pensamento do surdo é diferente do ouvinte. A memória linguística do aluno surdo tem necessidade de visão tridimensional. Segundo Vilhalva (2019, s.p.), palestrante dessa ação, "normalmente o aluno surdo é copista, pois muitas vezes a palavra não tem sentido para ele. Por exemplo a palavra cadeira. Ele copia a palavra cadeira, mas se pedir para ele colocar uma folha em cima da cadeira, não saberá onde está a cadeira". Explicou ainda que a Lingua de Sinais tem uma metodologia diferente do português.

Vilhalva (2019) destacou ainda que a maior parte dos alunos surdos não foram trabalhados linguisticamente. Chegam a universidade lendo e escrevendo pouco em português, chegam apenas fazendo cópias perfeitas. Para não serem copistas é importante a contextualização das palavras relacionando-as em diferentes situações, significados e associações para que ele estabeleça a aprendizagem.

A criança surda, muitas vezes, tem em casa pais que não utilizam Libras e sim o português. Esse é mais um dos fatores que contribui nesse processo de exclusão. Existe todo o contexto familiar que influencia na aprendizagem. Por isso é importante que o professor conheça o seu aluno para buscar técnicas que possam auxiliá-lo melhor na aprendizagem.

Cabe ao professor ensinar para seu aluno com legendamento em tempo real, e isso pode ser realizado com o uso de tecnologia em sala de aula. Uma técnica que pode ser utilizada é o uso do celular que tem no Google (ok google - Assistente com o Voice Match) a função permite que acesse usando a voz e automaticamente transcreve o texto em tempo real, onde o aluno pode visualizar a fala do professor.

Para Vilhalva (2019, s.p.) "não existe escola inclusiva pois para haver inclusão ela deve contemplar para o aluno surdo não apenas intérprete e sim a comunicação". Segundo essa palestrante, o intérprete não ensina, ele apenas interpreta, "Ele é considerado o pai ou a mãe linguística do surdo". 
A escola inclusiva deve ter a tecnologia a disposição com áudio visual, datashow para a prática do professor, bem como material disponibilizado com antecedência para o intérprete ter ciência do que vai ser trabalhado em aula. Não basta ter intérprete para os alunos, se os funcionários, gestores, professores não souberem a linguagem de sinais para se comunicar efetivamente com o aluno surdo.

Após a abordagem da palestrante, que é surda oralizada, um questionário foi aplicado aos participantes com questões gerais e específicas, como as aplicadas na primeira ação.

Dos participantes dessa ação, onze professores, um gestor e seis normalistas responderam o questionário. Para a questão 2 e questão 3, nenhum respondeu regular ou ruim.

$\mathrm{Na}$ terceira ação, os intérpretes de Libras do IFFar, participantes da primeira etapa da pesquisa, organizaram e aplicaram oficinas sendo que uma das intérpretes é ex-orientanda da pesquisadora. Esse momento contou também com a participação e colaboração dos orientandos da pesquisadora do mestrado em Ensino Científico Tecnológico da URI.

As oficinas foram divididas em dois encontros. No primeiro, todos os professores participaram da abordagem de Libras com o uso de sinais básicos com duração de $2 \mathrm{~h}$. Nessa ação os professores conheceram alguns sinais de tratamento e comunicação para os seus alunos surdos, como por exemplo: bom dia, boa tarde, boa noite, como perguntar nome, apresentação, entre outras.

Dois ex-alunos surdos dessa escola participaram contando sua experiência em sala de aula e fora dela. Suas dificuldades na aprendizagem e deram sugestões de como trabalhar alguns conceitos ou definições com alunos, sobre práticas inclusivas, para os participantes dessa ação.

Um ex-aluno, agora com 36 anos de idade e intérprete de Libras relatou que somente aos 29 anos aprendeu Libras. Todo o Ensino Fundamental e Médio não teve intérprete, mas mesmo assim ia bem na área das exatas como matemática, física, química e que o português era a disciplina mais dificil para ele. Relatou "que tanto na escola como na graduação de gestão pública era copia-cola, copia-cola, não teve aprendizagem significativa, pois o professor não 
usava técnicas diferenciadas como escrever no quadro usando cores diferentes, figuras, gravuras contextualizando o assunto". O fato da criança ser surda não é barreira para a aprendizagem, o professor deve proporcionar ao aluno surdo metodologias para que ele tenha um maior entendimento do assunto tratado.

A professora " $\mathrm{A}$ " participante das ações relatou que "às vezes o aluno surdo não aprende por falta de interesse". Será que é mesmo falta de interesse? Ou o método utilizado pelo professor não é o mais adequado? Cabe ao professor proporcionar o método, metodologia mais adequada para que ele se sinta inserido no processo de ensino.

A professora "B" achava que se mostrasse para o aluno surdo a imagem de um carro por exemplo, ele conheceria e saberia o que é carro. Chegou à conclusão que tem que mostrar os diversos tipos de carros, modelos, em vários contextos com abordagens diferentes para que ele assimile a palavra carro e relacione seu conceito, sendo um dos pontos positivos da oficina.

Outro ponto positivo foi a fala da professora " $\mathrm{C}$ ", que tem aluno surdo. No final do quarto encontro, ela disse: "Agora entendi porque eu tenho que mostrar para meu aluno, por exemplo, bola. O que é bola. Mostrar a bola em diversos contextos, para ele entender que existe vários tipos de bolas e que ela está inserida em vários contextos".

Figura 1: Contextualização de bola 


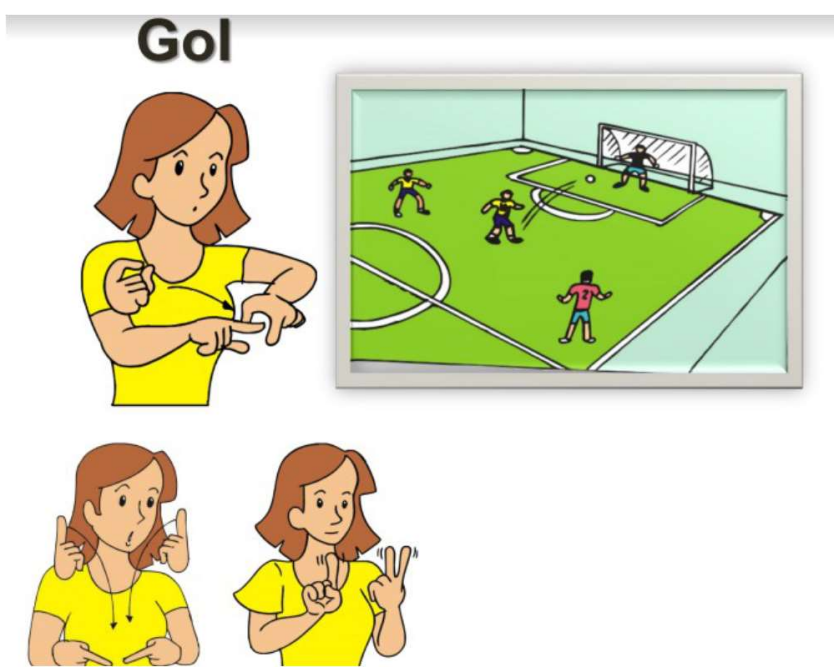

Fonte: DADA, 2015

A figura 1 pode ser usada para contextualizar bola, como relatou e concluiu anteriormente a professora $\mathrm{C}$.

Essas professoras conseguiram atingir o objetivo da formação proposta, entendendo algumas diferenças na forma como o seu aluno surdo aprende. Sendo o ponto máximo das ações quando alguns professores perceberam como se processa a aprendizagem de seus alunos surdos.

Participaram do $1^{\circ}$ encontro quarenta e seis professores e alunos do curso normal. Após a palestra, um questionário foi aplicado aos participantes com questões gerais e específicas, como as aplicadas na primeira e segunda ação.

Dos participantes dessa ação, quatorze professores responderam o questionário, um gestor e seis alunos do curso normal. Para a questão 2 e questão 3, nenhum respondeu regular ou ruim.

No segundo encontro da $3^{\mathrm{a}}$ ação os professores foram divididos em 2 grupos: Ensino Fundamental e Médio, Educação Infantil e de forma colaborativa, os professores trabalharam com técnicas inclusivas.

Um ponto relevante na constituição de um grupo de trabalho
colaborativo é, a nosso ver, a disposição para estudar e discutir
questões referentes à prática pedagógica, guiada pela teoria.
Professores da universidade e pesquisadores podem formar, junto com
professores escolares, um grupo com diferentes olhares, em que cada
um pode contribuir igualmente para o crescimento de todos.
(COELHO, 2017, p.349).

Foram sugeridas algumas técnicas para se trabalhar na elaboração das atividades tais como: imagens, tabelas, gráficos, material concreto, utilização 
de cores diferentes na produção da escrita no quadro, vídeos com legendas sobre o assunto abordado e tecnologias. Existem sites na internet com vídeos que foram organizados por professores surdos que podem ser utilizados pelo professor na sua prática pedagógica.

As atividades foram divididas em três momentos: no primeiro conhecerem figuras para elaboração de plano de aula.

O grupo da Educação Infantil apresentou a proposta de plano de aula de matemática com o objetivo de trabalhar quantidades. Utilizaram a imagem de um cachorro, dois cachorros. Cachorros de diferentes raças em diferentes contextos, também pode-se trabalhar unidades relacionando com as imagens, como representado na figura 2 .

Figura 2: Conteúdo de Quantidades
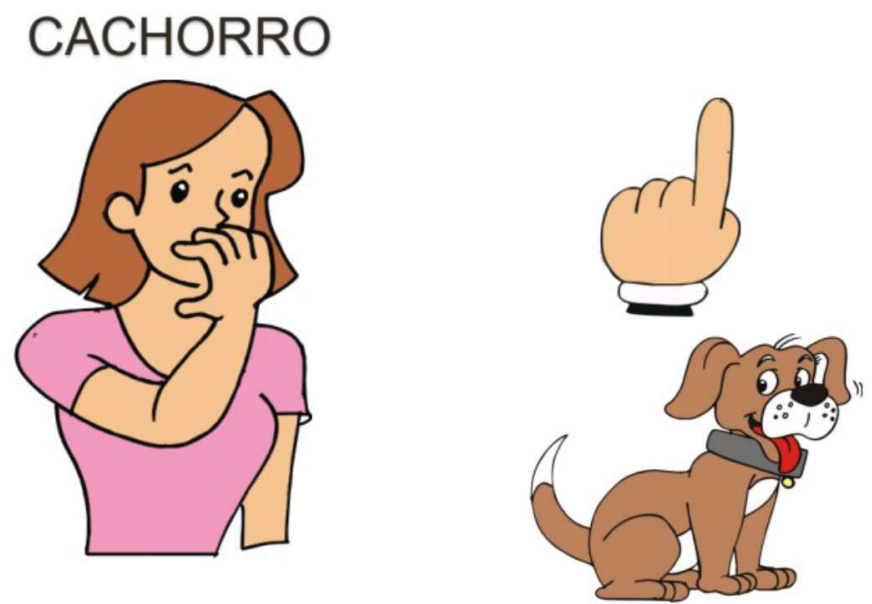

Fonte: DADA, 2015.

O professor pode iniciar suas atividades com a trilha em Libras para que seus alunos tenham conhecimentos de sinais para se comunicar com seus colegas surdos, representada na figura 3.

Figura 3: Trilha em Libras 

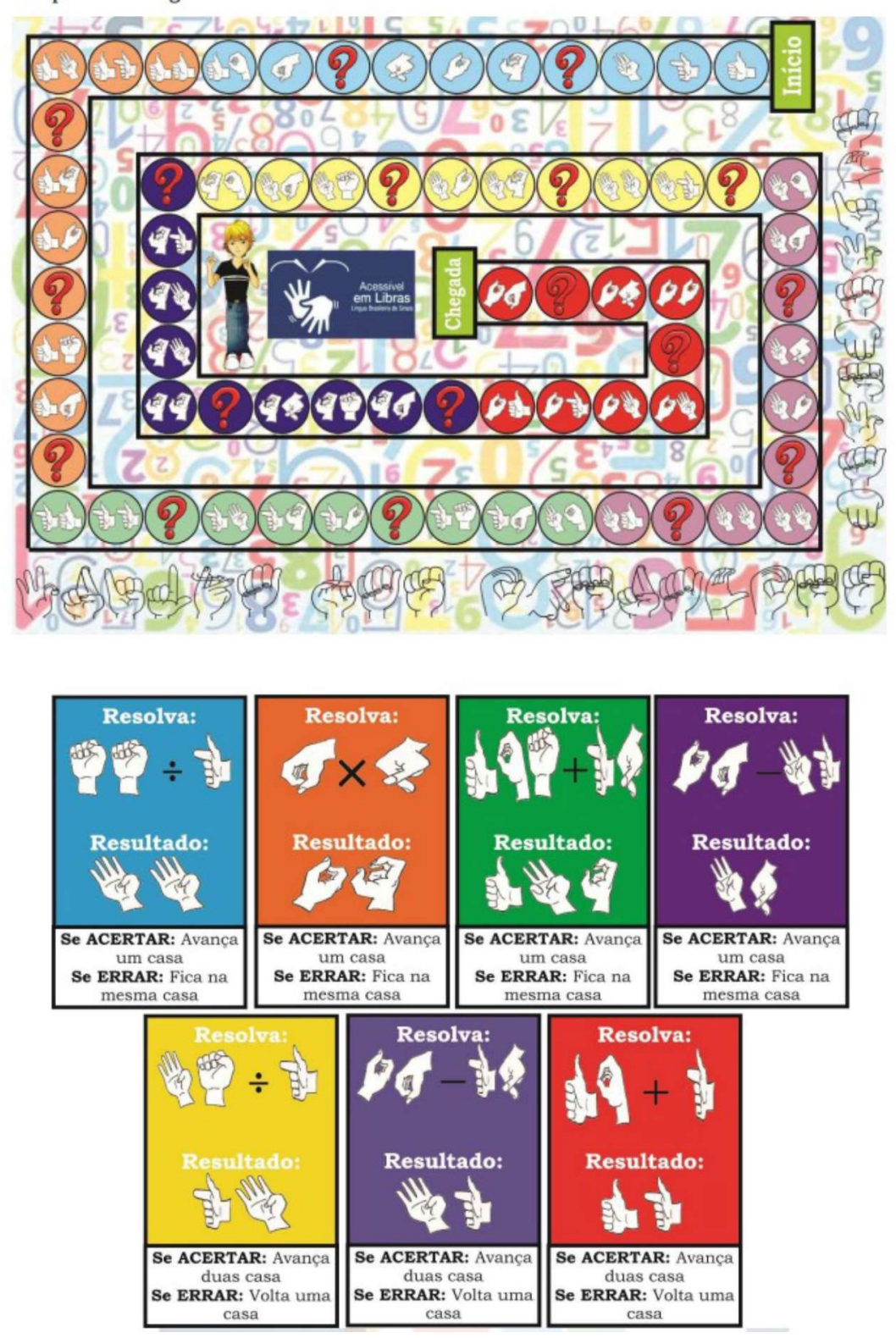

Fonte: NASCIMENTO; ARAÚJO; VIANA, 2016.

Alguns dos materiais utilizados para elaborar plano de aula com conceitos de unidades de medidas com respectivo site de pesquisa e acesso está exposto na figura 4.

Figura 4: Trabalhando medidas 


\section{Medidas de comprimento}
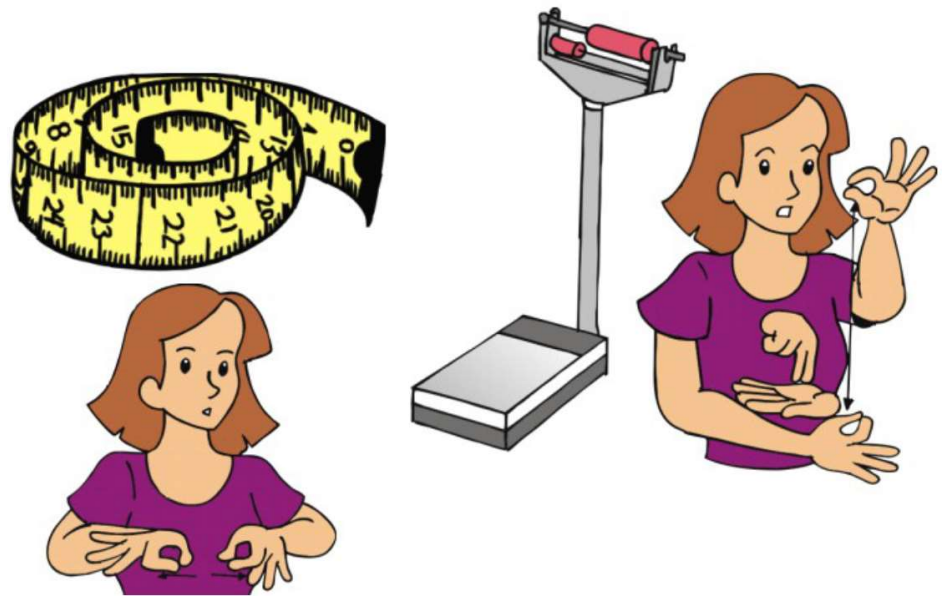

Fonte: DADA, 2015.

Para plano de aula com conteúdo de química, o professor pode usar a tabela de classificação periódica dos elementos como mostra a figura 5 .

Figura 5: Tabela periódica

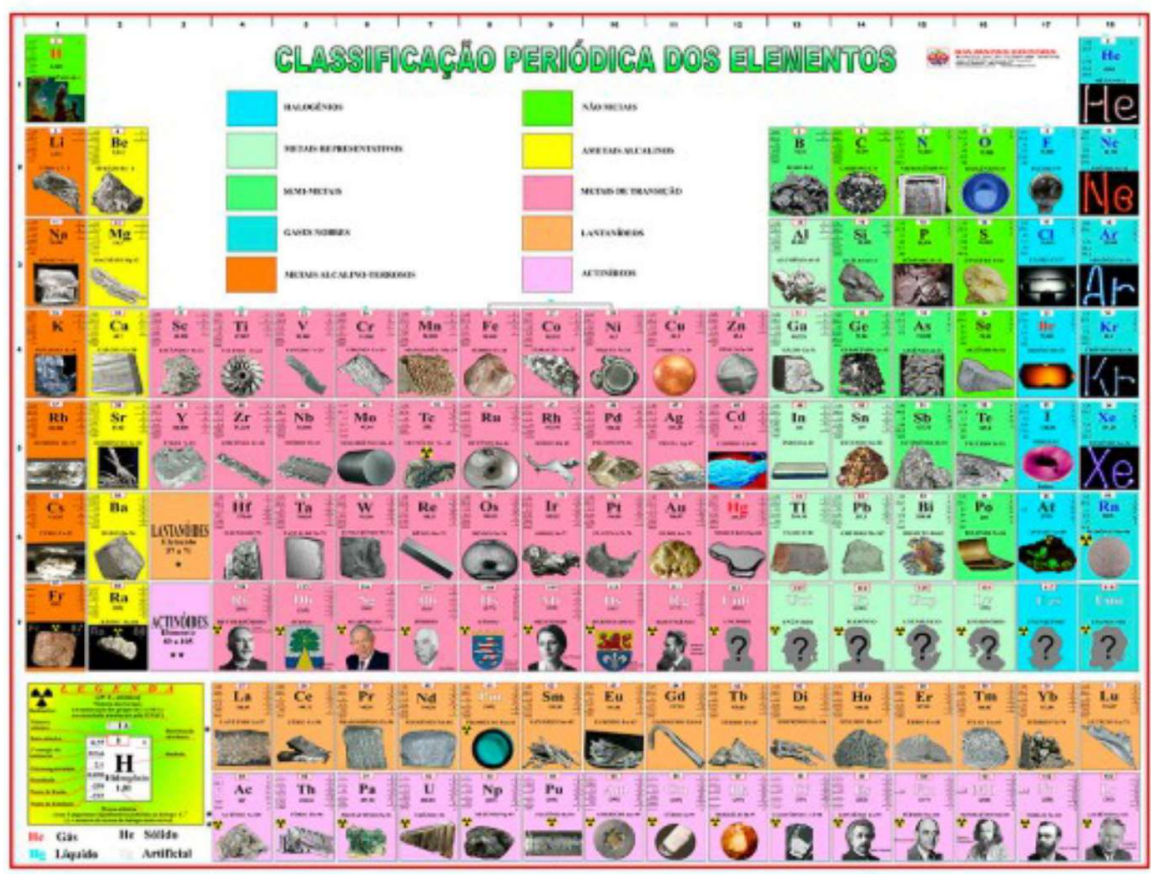

Fonte: https://www.lojaapoio.com.br/mapa/tabela-periodicailustrada--p

Existem também materiais para se trabalhar conteúdos de biologia, conforme apresentado na figura 6, que mostra o estômago humano.

Interfaces da Educ., Paranaíba, v.10, n.30, p. 290 - 314, 2019 
Figura 6: Estômago

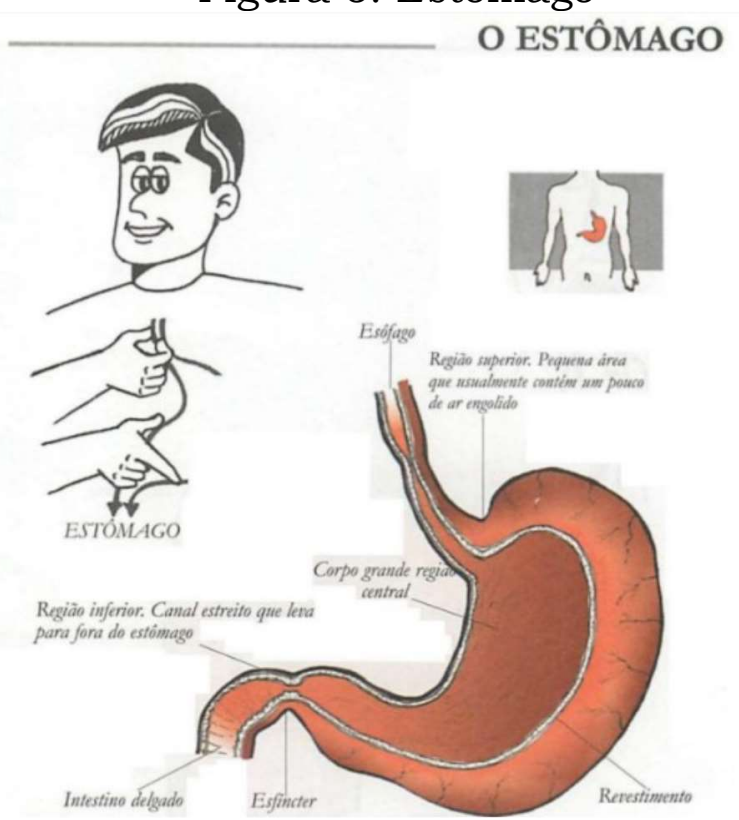

Fonte: MENEGUETE; GUINTEIRO, 1998, p.10.

Com algumas dessas sugestões apresentadas nas figuras, os participantes do grupo do Ensino Fundamental e Médio elaboraram planos de aula e essa forma, no momento das apresentações houve troca de experiência entre os grupos e novas sugestões foram incorporadas em suas propostas. Segundo Damiani (2008, p.218) “o trabalho colaborativo entre professores apresenta potencial para enriquecer sua maneira de pensar, agir e resolver problemas, criando possibilidades de sucesso à dificil tarefa pedagógica".

No segundo momento, elaboraram avaliação utilizando questões do tipo "Analise as afirmativas e julgue com V (Verdadeira) ou F (Falsa)" como sugerido pelas intérpretes que atuaram nas oficinas.

Recomenda-se que as assertivas a serem julgadas tenham textos curtos e com termos mais comumente usados. Isso significa que ao invés de utilizar termos mais rebuscados ou complexos, deve-se priorizar sinônimos mais comuns.

Um dos grupos elaborou uma avaliação de geografia contento questões visuais envolvendo verdadeiro e falso; questões curtas com pouco texto e mais imagens, como por exemplo a questão 1 .

Questão 1:

São capitais brasileiras: 

a. ( ) Paris
b. ( ) João Pessoa
c. ( ) Tóquio
d. ( ) São Luís
e. ( ) Porto Alegre

Questões de múltipla escolha.

Assim como as questões de julgamento, outra opção bem aceita para a avaliação de estudantes surdos é o tipo múltipla escolha. Importante observar a elaboração da questão de forma concisa, com clareza e com o mínimo de possibilidade de dúvidas na interpretação, dando destaque a termos específicos como forma de auxiliar, como exemplo a questão 2 que envolve conteúdo de Ciências.

Questão 2:

Assinale a alternativa INCORRETA:

a. ( ) Gelo é a água em estado sólido

b. ( ) Vapor é a água em estado gasoso

c. ( ) A temperatura de ebulição da água é $100^{\circ} \mathrm{C}$

d. ( ) A água a $100^{\circ} \mathrm{C}$ está no estado líquido

e. ( ) A água é inodora, insípida e incolor

Questões dissertativas (subjetivas)

Caso seja imprescindivel a existência de questões dissertativas, recomenda-se que estas sejam em menor quantidade em relação ao total de questões. Por exemplo, se há 10 questões, sugere-se até 3 questões com respostas a serem construídas em formato dissertativo.

Além disso, o texto da questão deve priorizar o entendimento da mesma, elaborado de forma clara e com previsão de respostas objetivas. Como exemplo a pergunta: O que é software? Nessa e em outras questões o aluno tem o auxílio do intérprete. O professor da disciplina tem a opção de elaborar a prova e ter o auxílio do intérprete no momento da aplicação. O papel do intérprete deve ser o de interpretar para o estudante surdo ou deficiente auditivo as questões da atividade. 
No terceiro momento, após as apresentações do plano de aula e avaliação, as intérpretes responsáveis pelas oficinas mostraram alguns sites com sugestões de materiais disponíveis. Foram apresentados 3 sites com materiais das disciplinas de Matemática e Física, 1 site de Química e 2 sites de Biologia (Figura 7). Além de materiais encontrados em Brasil (2013).

Figura 7: Sugestões de sites com materiais inclusivos

\begin{tabular}{|c|c|}
\hline Disciplinas & Endereços dos sites com materiais inclusivos \\
\hline $\begin{array}{l}\text { Matemátic } \\
\text { a }\end{array}$ & $\begin{array}{l}\text { https://editorarealize.com.br/revistas/cintedi/trabalhos/TRABALHO } \\
\text { _EV060_MD1_SA7_ID4160_23102016231317.pdf } \\
\text { https:// www.youtube.com/playlist?list=PLCC22z6WzHdVbbEKJK0k } \\
\text { HofRal8f5fD-N } \\
\text { https://pt.slideshare.net/abreusurdoAbreu/sinais-desenho-parte-2 }\end{array}$ \\
\hline Física & $\begin{array}{l}\text { https://www.youtube.com/watch?v=wYpyMv1UOCk } \\
\text { https://www.youtube.com/watch?v=08bjFqKfV_4\&list=PLCC22z6Wz } \\
\text { HdUR14I6St5-g1i89_Cf5lqT\&index=29 } \\
\text { https://www.youtube.com/watch?v=Uo_9p_Tpj_Q\&list=PLCC22z6Wz } \\
\text { HdUR14I6St5-g1i89_Cf5lqT\&index=5 }\end{array}$ \\
\hline Química & $\begin{array}{l}\text { https://pt.scribd.com/doc/261601388/Apostila-de-Quimica-em- } \\
\text { Libras }\end{array}$ \\
\hline Biologia & $\begin{array}{l}\text { https://pt.slideshare.net/valpimentinha/manual-de-ciencias-e- } \\
\text { geografia-em-libras } \\
\text { http:/ / biolibras.com.br/category/traducoes / ?paged2=1 }\end{array}$ \\
\hline
\end{tabular}

Fonte: Organizado pelas autoras

Participaram dezoito professores e alunos do curso normal. Após a abordagem das palestrantes, um questionário foi aplicado com questões gerais e específicas, como as aplicadas nas primeiras ações.

Dos professores e alunos do curso normal, participantes dessa ação, dez responderam o questionário e desses, dois eram normalistas. Nessa ação nenhum gestor participou. Tanto para a questão 2 como para a questão 3 , nenhuma resposta foi regular ou ruim.

A $4^{\mathrm{a}}$ ação proposta pela pesquisadora, ficou como sugestão para as gestoras da escola, pois apenas houve uma intenção de continuidade dessa ação por parte delas. Ainda não se sabe se será comtemplada ou não. 
Foi constatado como um ponto negativo dos 4 encontros propostos com ações formativas, que alguns professores não se motivaram demonstrando desinteresse pela formação. Houve uma diminuição do número de participantes em cada encontro das ações. Talvez muitos destes não estejam preparados para o processo de inclusão ou por não terem alunos surdos em suas classes ou por falta de interesse mesmo. Muitas vezes fala-se que faltam formações, mas quando se tem a oportunidade, nem todos participam efetivamente, por diferentes motivos.

A inclusão escolar é um desafio e muitos alunos com deficiência permanecem nas escolas sem condições de aprendizagem adequadas, desse modo, é necessário redefinir práticas pedagógicas que sejam compativeis com a inclusão escolar, envolvendo a formação de professores para o trabalho em classes inclusivas e a adaptação curricular, objetivando promover um ensino de qualidade para todos (COLLING; GELLER, 2019).

Em todas as ações a avaliação das atividades e oficinas desenvolvidas foram bem avaliadas pelos participantes com nenhuma resposta regular ou ruim para as questões consideradas pertinentes para análise.

\section{Considerações Finais}

Para que a inclusão aconteça realmente, a comunidade escolar (professores, gestores, alunos) devem estar preparados para as diferenças encontradas no ambiente escolar. No contexto da educação inclusiva é preciso ter abertura e aceitação ao diferente para que as ações possam de fato influenciar no processo de ensino e aprendizagem. De nada adianta ações de sensibilização e formação sem o envolvimento efetivo de todos, devendo a formação docente articular relações entre a teoria e a sua prática.

Para que não ocorram lacunas ou barreiras educacionais faz-se necessária a formação continuada em todas as áreas do conhecimento e em todos os níveis de ensino. Nesse sentido se deve oferecer na formação continuada, propostas envolvendo processos inclusivos para que os professores que atuam com alunos surdos sejam verdadeiramente inseridos nesse ambiente escolar (FRANZIN; GELLER, 2019). 
Acredita-se que deve ser um trabalho em parceria, dessa forma o diálogo entre ambos deve prevalecer, trocando ideias e sugestões em relação as adaptações nas aulas, provas, entre outras atividades. Trabalho em equipe com reuniões, conversas, trocas, sendo realizados colaborativamente.

As ações podem ser oferecidas por meio de encontro entre docentes, intérpretes, setor pedagógico e demais núcleos responsáveis pela inclusão no ambiente escolar e também por meio de ciclos de estudos e compartilhamento dos conteúdos a serem trabalhados pelos professores antecipadamente para os intérpretes. Assim como avaliações e trabalhos de modo a verificar se as adaptações realizadas estão de acordo com as necessidades dos alunos surdos.

Nessa perspectiva, as ações foram compartilhadas entre os intérpretes de Libras e professores, fazendo com que todos fossem responsáveis pelo processo de aprendizagem, compartilhamento e disseminação do conhecimento adquirido, possibilitando ao professor se tornar mais preparado e participante do processo.

Contudo, deve-se refletir sobre o processo de formação continuada, o que requer o redimensionamento das ações propostas e o estabelecimento de novas formas de abordagens, mas acima de tudo a postura do professor frente as oportunidades que lhe são ofertadas. Se não partir de seu interesse não resultará em mudanças significativas nesse processo de inclusão. O professor tem que ter um olhar diferenciado e estar aberto para aprender e buscar novas práticas para o aprendizado de seu aluno, seja surdo ou não.

\section{Referências}

BORBA, M.C.; ALMEIDA, H.R.L.; GRACIAS, T.A.S. Pesquisa em ensino e sala de aula: diferentes vozes em uma investigação. 1. ed. Belo Horizonte: Autêntica, 2018.

BRASIL. Resolução CNE/CEB n ${ }^{\circ}$ 2, de 11 de setembro de 2001. Disponível em: < http://www.planalto.gov.br/ccivil_03/leis/2002/110436.htm >. Acesso em: 8 dez. 2018. 
BRASIL. Portaria $n^{\circ}$ 1063, de 10 de setembro de 2013. Manual de orientações para adaptações/adequações curriculares e terminalidades específicas. Disponivel em: < >. Acesso em: 8 dez. 2018.

COELHO, M.AV.M.P. Grupos colaborativos na formação de professores: uma revisão sistemática de trabalhos brasileiros. Zetetiké. Campinas, SP, v. 25, n.2, maio/ago.2017. Disponível em: < https://www.fe.unicamp.br/publicacoes/lancamentos/5513 >. Acesso em: 10 jun. 2019.

COLLING, A.P.S.; GELLER, M. Reflexões sobre a formação de professores na perspectiva do ensino de matemática para uma aluna com Síndrome de Jacobsen. XV CIAEM-IACME, Medellín, Colombia. Disponivel em: < https://conferencia.ciaem-

redumate.org/index.php/xvciaem/xv/paper/viewFile/337/352 >. Acesso em 08 set. 2019.

DADA, Z. Slides. Campo Grande. MS. Publicado em 14 dezembro 2015. Disponivel em: < https://pt.slideshare.net/abreusurdoAbreu/sinais-desenho >. Acesso em: 24 mai. 2018.

DAMIANI, M.F. Entendendo o trabalho colaborativo em educação e revelando seus benefícios. Educar. Curitiba: UFPR, n. 31, p. 213-230, 2008. Disponivel em: < www.scielo.br/ scielo.php?pid=S0104-40602008000100013\&script >. Acesso em: 22 jun. 2019.

FELIPE, M.A.; GELLER, M. Educação inclusiva na formação inicial: percepções de licenciandos em Pedagogia e Matemática. XV CIAEM-IACME, Medellin, Colombia. Disponível em: < https://conferencia.ciaemredumate.org/index.php/xvciaem/xv/paper/viewFile/686/105 >. Acesso em 09 set. 2019.

FRANZIN, R.F.; ZWAN, L.D.; ROSINSKI, A.M. A educação de surdos e o contexto tecnológico: uma experiência com a lousa digital. ENEM, 2016. Disponivel em < http://www.sbembrasil.org.br/enem2016 > . Acesso em: 20 set. 2018.

FRANZIN, R.F.; GELLER, M. Percepções dos professores de matemática e interrpretes de Libras: reflexões sobre o processo de inclusão. $8^{\text {th }}$ International Congress on Education and Learning. Porto, Portugal. 2019. Disponivel em < Interfaces da Educ., Paranaîba, v.10, n.30, p. 290 - 314, 2019 
http://oneducationandlearning.com/congress/call-for-papers / >. Acesso em 23 set. 2019.

GERHARDT, T.E; SILVEIRA, D.T. (org.) Métodos de Pesquisa. Universidade Aberta do Brasil - UAB/UFRGS e Curso de Graduação Tecnológica Planejamento e Gestão para o Desenvolvimento Rural da SEAD/UFRGS. Porto Alegre: Editora da UFRGS, 2009. Disponível em < https:/ / books.google.com.br/books?hl=pt-BR\&lr=\&id=dRuzRyEIzmkC\&oi= fnd\&pg=PA9\&dq=metodo + de + pesquisa + descritiva + participativa\&ots $=92 S f Y \_i$ vIH\&sig=KxatC-YqyXx08AJJ4aLGttyUpDM\#v=onepage\&q\&f=false >. Acesso em 06 fev. 2019.

INEP. Censo Escolar. 2018. Disponivel em: < http://portal.inep.gov.br/artigo//asset_publisher/B4AQV9zFY7Bv/content/censo-escolar-2018-revelacrescimento-de-18-nas-matriculas-em-tempo-integral-no-ensinomedio/21206 >. Acesso em: 27 ago. 2019 MIRANDA, C. J. A.; MIRANDA, T. L. O Ensino de Matemática para Alunos Surdos: Quais os desafios que o professor enfrenta? Revemat: Revista Eletrônica de Educação Matemática. Florianópolis, v. 06, n. 1, p.31-46, 2011. Disponivel em:

https://periodicos.ufsc.br/index.php/revemat/article/view/10.5007-19811322.2011v6n1p31/21261>. Acesso em: 15 mar. 2107.

NASCIMENTO, F.R.F.M.; NASCIMENTO, J.L.G.; SOUZA, G.D.; CAVALGANTI, R.S. Quais os desafios que o professor enfrenta para ensinar aos alunos surdos? II CONEDU. v.1, 2015. Disponivel em:

MENEGUETE, D.; GUINTEIRO, J.M.W. Manual de ciências e geografia. Curitiba: SEED/SUED/DEE. 1998. Disponivel em: < http://www.editorarealize.com.br/revistas/ conedu/anais.php >. Acesso em: 24 mai. 2018.

NASCIMENTO, G. M; GELLER, M. Ensino de ciências e políticas públicas de educação inclusiva: um estudo teórico. X ENPEC - Encontro Nacional de Pesquisa em Educação em Ciências, ABRAPEC, Águas de Lindóia, SC, 2015. Disponivel em: < http://www.abrapecnet.org.br/enpec/xenpec/anais2015/resumos/R1661-1.PDF >. Acesso em 08 set. 2019. 
NASCIMENTO, A.M.S.; ARAÚJO, R.G.B.; VIANA, K.S.L. Trilha das operações matemáticas em libras: uma proposta didática. II CINTEDI - Congresso Internacional de Educação Inclusiva. 2016. Disponível em: < https://editorarealize.com.br/revistas/cintedi/trabalhos/TRABALHO_EV06 0_MD1_SA7_ID4160_23102016231317.pdf >. Acesso em: 27 mai. 2019.

PANITZ, T. A definition of collaborative us cooperative learning. 1996. Disponivel em:

http://www.lgu.ac.uk/deliberations/collab.learning/panitz2.html >. Acesso em: 18 ago. 2018.

RABELO, L.C.C. Ensino colaborativo como estratégia de formação continuada de professores para favorecer a inclusão escolar. Dissertação de mestrado. Universidade Federal São Carlos. 200 fl. São Carlos. 2012. Disponível em: < https://repositorio.ufscar.br, bitstream , handle , ufscar >. Acesso em: 23 set. 2019.

TORRES, P.L.; IRALA, E.A. Aprendizagem colaborativa: teoria e prática. Coleção Agrinho. p.61-93, 2014. Disponivel em: < https:www.agrinho.com.br/site/wpcontent/uploads/2014/09/2_03_Aprendizagem-colaborativa.pdf >. Acesso em: 06 jun. 2019.

VILHALVA, S. Palestra "Possibilidades de metodologias para alunos surdos". Santo Ângelo/RS. 2019.

ZWAN, L. D.; FRANZIN, R.F.; RETZLAFF, E.; ROSINSKI, A.M. Matemática inclusiva para alunos surdos da educação básica. ENEM, 2016. Disponível em < http://www.sbembrasil.org.br/enem2016 >. Acesso em: 20 set. 2018. 